Article

\title{
Effects of Bentonite on $p$-Methoxybenzyl Acetate: A Theoretical Model for Oligomerization via an Electrophilic-Substitution Mechanism
}

\author{
Manuel Salmón ${ }^{1, *}$, Rene Miranda ${ }^{2}$, Ines Nicolás-Vázquez ${ }^{2, *}$, Yolanda Marina Vargas-Rodriguez ${ }^{2}$, \\ Julian Cruz-Borbolla ${ }^{3}$, María Isabel Medrano ${ }^{1}$ and José Antonio Morales-Serna ${ }^{1}$
}

1 Instituto de Química de la Universidad Nacional Autónoma de México, Circuito Exterior, Ciudad Universitaria Coyoacán 04510, México, D.F., Mexico;

E-Mail: morser@correo.unam.mx (J.A.M.-S)

2 Sección de Química Inorgánica, Fisicoquímica y Química Orgánica, Departamento de Ciencias Químicas, Facultad de Estudios Superiores Cuautitlán, Universidad Nacional Autónoma de México, Cuatitlán Izcalli, 54740, Estado de México, Mexico; E-Mails: mirruv@yahoo.com.mx (R.M.); ym_vargas@yahoo.com.mx (Y.M.V.-R.)

3 Área Académica de Química, Universidad Autónoma del Estado de Hidalgo, Unidad Universitaria, Km 4.5 Carretera Pachuca-Tulancingo, Mineral de Reforma, 42184, Hidalgo, Mexico; E-Mail: jcruzborbolla@yahoo.com.mx (J.C.-B.)

* Authors to whom correspondence should be addressed; E-Mails: salmon@unam.mx (M.S.); nicovain@yahoo.com.mx (I.N.-V.).

Received: 29 November 2010; in revised form: 14 February 2011 / Accepted: 15 February 2011 / Published: 21 February 2011

\begin{abstract}
Tonsil Actisil FF, a commercial bentonitic clay, promotes the formation of a series of electrophilic-aromatic-substitution products from para-methoxybenzyl acetate in carbon disulfide. The molecules obtained correspond to linear isomeric dimers, trimers, tetramers and a pentamer, according to their spectroscopic data. A clear indication of the title mechanistic pathway for the oligomerization growth was obtained from the analysis of a set of computational-chemistry calculations using the density-functional-theory level B3LYP/6-311++G(d,p). The corresponding conclusions were based on the computed dipole moments, the HOMO/LUMO distributions, and a natural-populations analysis of the studied molecules.
\end{abstract}


Keywords: bentonitic clay; para-methoxybenzyl acetate; oligomerization; electrophilic aromatic substitution; DFT calculations

\section{Introduction}

Benzyltoluenes are of industrial interest due to their application as insulating oils in high-voltage electrical devices [1], in the production of termiticide emulsions that demonstrate good penetration and emulsion stability [2], and in the preparation of corrosion-protection products [3]. Our research group previously developed and reported a strategy to obtain oligomeric toluene compounds with solid acid catalysts using thermal energy and ultrasound [4]. Thus, when ortho- and para-benzyltoluenes were studied, the outcome of the oligomerization reactions was found to be dependent of the amount of catalyst used, reaction time, temperature and the presence of pyridine as a competitive inhibitor. The study was carried out using Tonsil Actisil FF (TAFF), a commercial bentonite clay that has long been employed by our research group as a Brønsted-Lowry and Lewis acid catalyst in different chemical reactions [5-14]. An electrophilic aromatic substitution pathway has been suggested for the oligomerization reaction [15], while a low toluene/ $\mathrm{BzCl}$ ratio is necessary to obtain the oligomers [16,17].

In this context, we considered the possibility of carrying out the reaction of para-methoxybenzyl acetate in the presence of Tonsil Actisil FF to obtain oligomeric compounds, followed by a theoretical analysis that rationalizes the observed products and some of the key reaction steps. Previous studies carried out by our research group have established the importance of an electrophilic attack in similar reactions [18]. Despite the complete absence of experimental data on the structures of the transition states, calculated transition-state geometries are now commonplace thanks to the development of software that provides tools to propose transition states. Thus, the aim of this paper is to report on the conversion of para-methoxybenzyl acetate with TAFF, producing isomeric diphenylmethane and a series of linear oligomers with a progressive number of units. This is accompanied by computationalchemistry calculations performed to establish a validated mechanistic pathway to explain the growth of the obtained linear oligomers.

\section{Results and Discussion}

To investigate the novel catalytic capabilities of TAFF, this work studied the transformation of para-methoxybenzyl acetate (1). Despite the Lewis and Brønsted-Lowry acid character of the studied clay, its acidity is very low in comparison with sulfuric or triflic acids [19]. Thus, the phenylmethanes 2-4 and linear oligomers 5-8 were obtained when the reaction was carried out in carbon disulfide at room temperature. However, when the temperature was increased to $46{ }^{\circ} \mathrm{C}$, the linear oligomers 9 and 10 were obtained. The structure of each isolated compound is displayed in Figure 1, where it can be seen that the phenylmethanes $\mathbf{2}$ and $\mathbf{3}$ are ortho-substituted with respect to $\mathrm{MeO}$, an electron-donating group, whereas 4 is formed by an ipso-substitution. All other molecules are symmetrically substituted linear benzylic oligomers formed through an electrophilic aromatic substitution (EAS) with three, four or five linked aromatic units. In the oligomers $\mathbf{2 , 5}$ and $\mathbf{8}$, the acetyl unit remains present, but it is 
absent in $\mathbf{3}$ and $\mathbf{7}$, yielding a methyl group, as previously seen in pentamethylbenzyl cation reduction [20] by the addition of a hydride provided by the clay [21]. However, this process could results from a catalytic transfer hydrogenation from an organic donor-molecule species to any of the variety of organic acceptors formed in the reaction medium [22]. Trimer 6 is the only isolated compound possessing a benzylic $\mathrm{OH}$ group, which is probably formed after the acyl hydrolysis of $\mathbf{5}$. Finally, when the temperature is increased, the promotion of the longer linear oligomers $\mathbf{9}$ and $\mathbf{1 0}$ is obtained by further condensation with other para-methoxybenzylic carbenium ions or by an ipso substitution.

Scheme 1. Oligomerization reaction products.

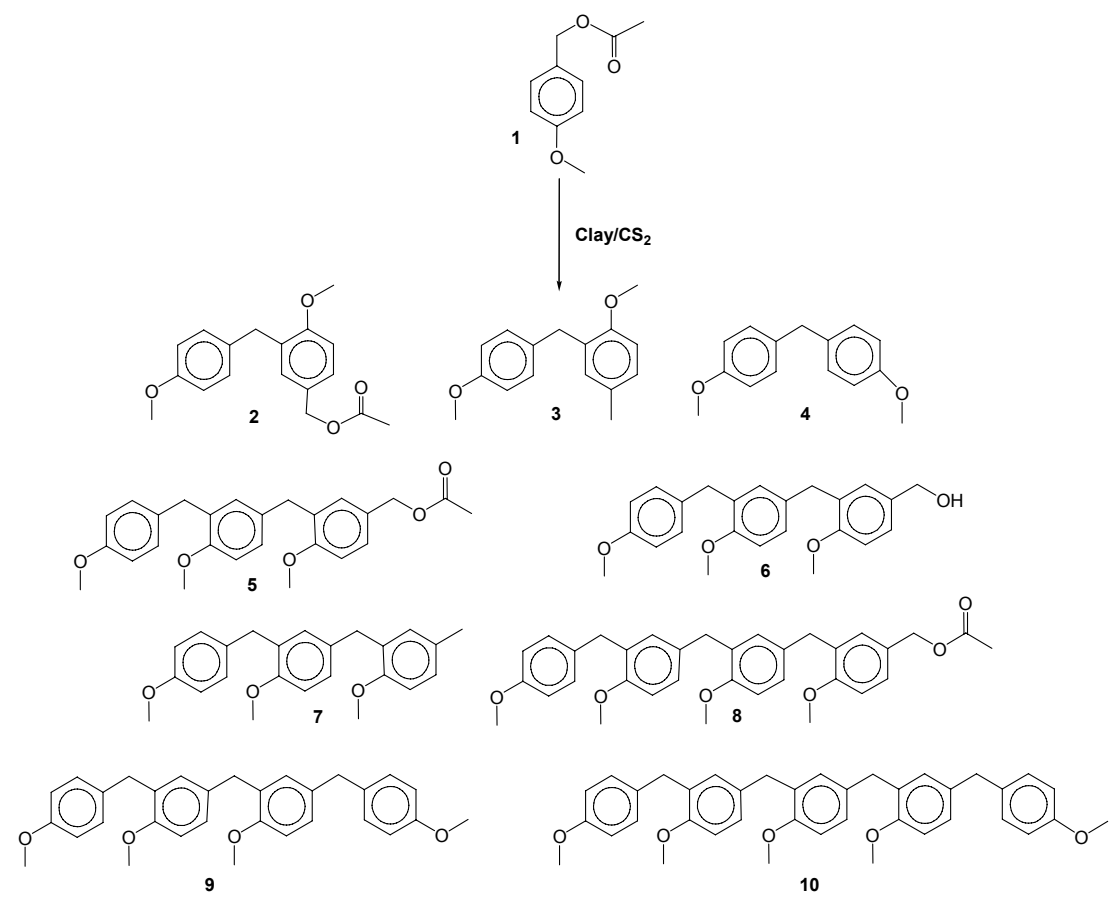

Reagents and conditions: $1.0 \mathrm{~g}$ of clay, $5 \mathrm{~g}$ of $p$-methoxybenzyl acetate, $40 \mathrm{~mL}$ of $\mathrm{CS}_{2}$, r.t., $76 \mathrm{~h}$.

Figure 1. B3LYP/6-311++G(d,p) energy profile for the carbenium ion formation.

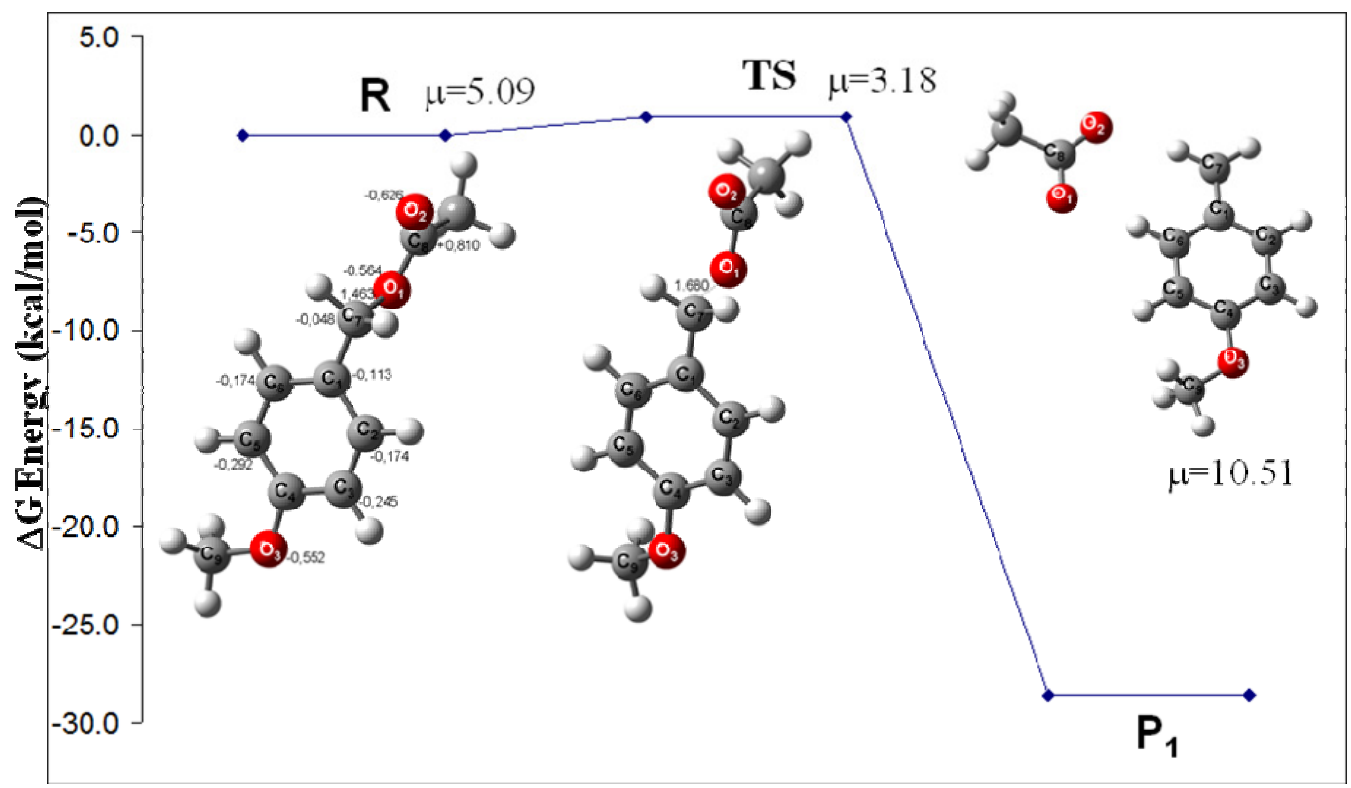


Two possibilities were considered to explain the EAS mechanism of the para-methoxybenzyl acetate reactions yielding 2-10 (Scheme 1) via the para-methoxybenzyl carbenium ion. The clay may provide protons or electrons to the neutral molecule to assist the carbocation induction at the beginning of the process. To analyze this possibility, the benzylic $\mathrm{CH}_{2}-\mathrm{OAc}$ bond distance in the monomer was computed with a charge of -1 and a length of $1.680 \AA$ (adding one electron) and with a charge of +1 and a length of $1.418 \AA$ (removing an electron) (Figure 1). It is important to note that, in the neutral molecule, the $\mathrm{CH}_{2}-\mathrm{OAc}$ bond distance is $1.463 \AA$. With these bond lengths, the clay may provide an electron to enlarge the $\mathrm{CH}_{2}$-OAc bond, easing the corresponding rupture to generate an electrophilic species. In this sense, 2 must be formed when this carbenium ion, with a dipole moment (DM) of $10.51 \mathrm{D}$ and located in the plane of the benzene ring, interacts with the $3.17 \mathrm{D}$ DM of a neutral species. In this way, the interaction between both species with an ortho position to the $\mathrm{MeO}$ group on the benzene ring will be favored (Figure 2). Additionally, this mechanism may suggest that the formation of $\mathbf{3}$ is obtained from the dimeric carbenium ion (Figure 3), which is reduced by a hydride provided by the clay, yielding the corresponding methyl group [20].

Figure 2. a) Neutral species of para-methoxybenzyl acetate. b) The carbenium ion of para-methoxybenzylic acetate. c) The HOMO of para-methoxybenzyl acetate and the LUMO of the para-methoxybenzyl carbenium ion $\left(\Delta \mathrm{E}_{\mathrm{HOMO}-\mathrm{LUMO}}=1.69 \mathrm{eV}\right)$. d) The optimized B3LYP/6-311++G(d,p) geometries for 2. The calculated NPA charges are reported in $\mathbf{e}^{-}$.

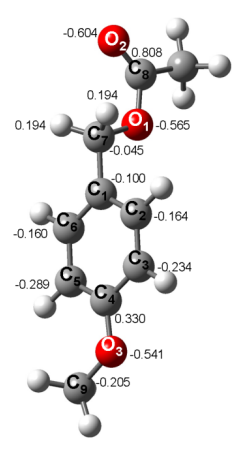

a)

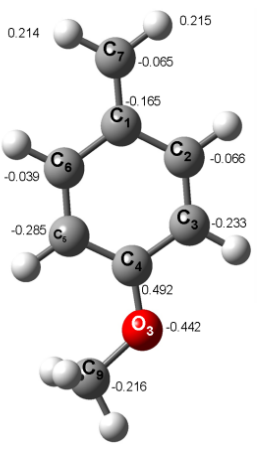

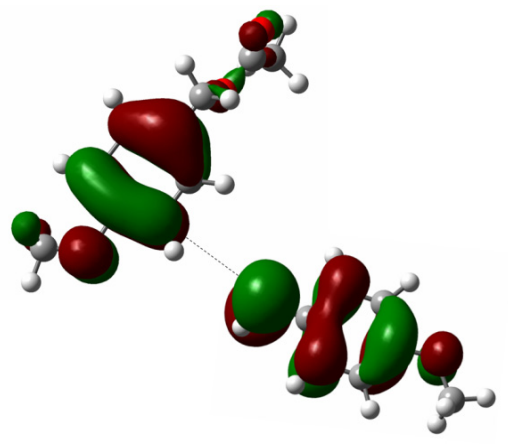

c)

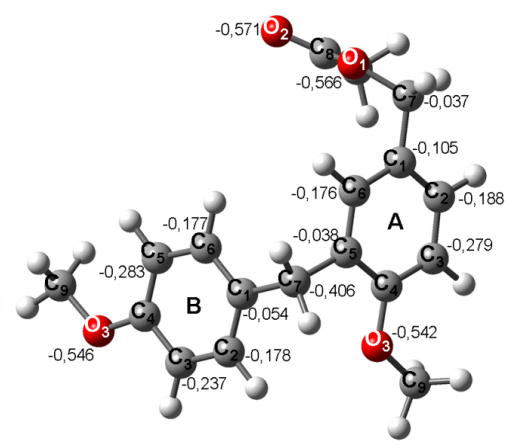

d)

Figure 3. a) The LUMO of the dimeric carbenium ion that yields 3. b) The optimized B3LYP/6-311++G(d,p) geometries for 3. The calculated NPA charges are reported in $\left.\mathbf{e}^{-} . \mathbf{c}\right)$ The carbenium dimer. d) The interaction between the LUMO of the charged carbenium dimer with the HOMO of $\mathbf{3}$ to yield the corresponding trimer $\mathbf{7}$.

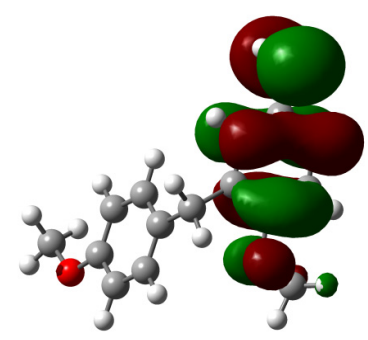

a)

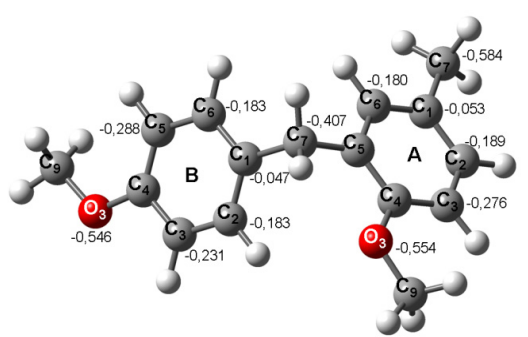

b)

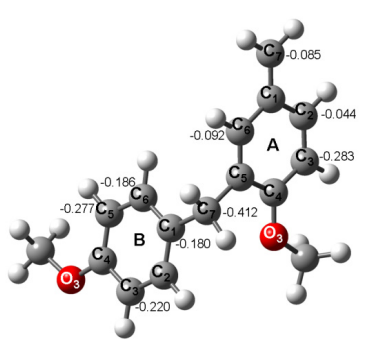

c)

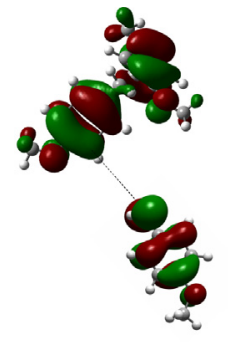

d) 
Consequently, all compounds possessing a benzylic-ester substituent group, after dimerization, are able to continue the chain enlongation assisted by the corresponding benzylic carbenium ion. Thus, the oligomers 5 and $\mathbf{8}$ may be formed by two possible routes. The first route implicates an interaction between the charged carbenium dimer $\mathbf{2}$ or a charged carbenium trimer $\mathbf{5}$ with the original substrate (basic unit) to yield the corresponding trimer $\mathbf{6}$ and tetramer 8. This model resembles the process of formation of 2 (Figure 4).

Figure 4. a) The interaction between the LUMO of the charged carbenium dimer with the HOMO of the original substrate to yield the corresponding oligomer $\mathbf{5}$. b) The interaction between the LUMO of the charged carbenium trimer with the HOMO of the original substrate to yield the corresponding oligomer 8. c) Two possible routes to obtain 5 . The energy difference between the HOMO of the neutral species and the LUMO of the dimer carbenium is $\Delta \mathrm{E}_{\text {HOMO-LUMO }}=1.28 \mathrm{eV}$; therefore, this interaction is more feasible. d) The optimized B3LYP/6-311++G(d,p) geometries for 5. The calculated NPA charges are reported in $\mathbf{e}^{-}$.

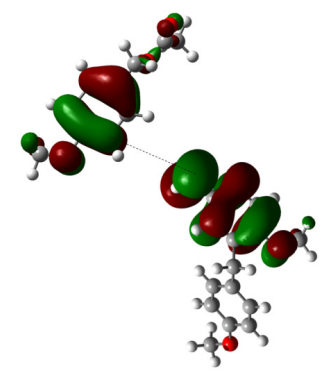

a)

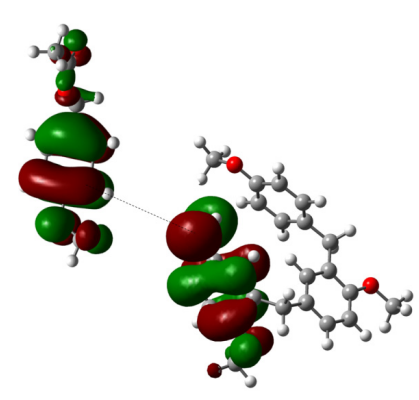

b)

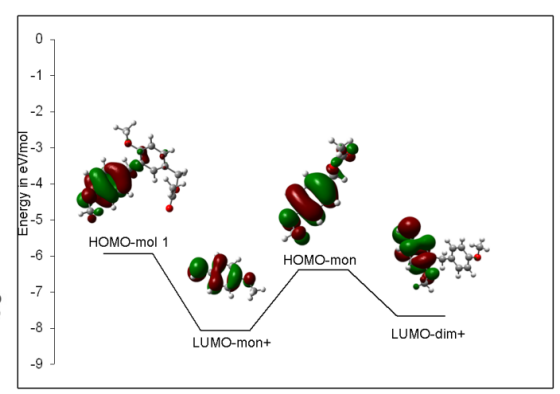

c)

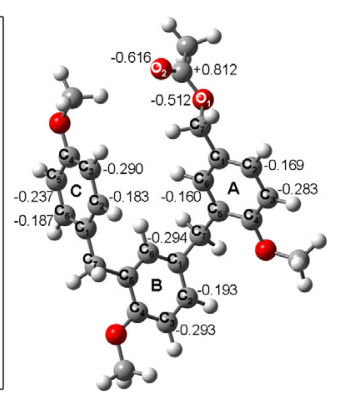

d)

Figure 5. a) The oligomer $\mathbf{5}$ is obtained from the benzylic carbenium monomer and the dimer 2. b) The HOMO of $\mathbf{5}$ and the LUMO of methoxybenzyl carbenium ion that yield tetramer 8. c) The HOMO of $\mathbf{2}$ and the LUMO of the charged carbenium dimer that yield $\mathbf{8}$. d) According to the graph, three possible routes could lead to $\mathbf{8}$. The energy difference between the HOMO of the neutral species and the LUMO of the trimer carbenium is $\Delta \mathrm{E}_{\mathrm{HOMO}-\mathrm{LUMO}}=1.06 \mathrm{eV}$; therefore, this interaction is more feasible.

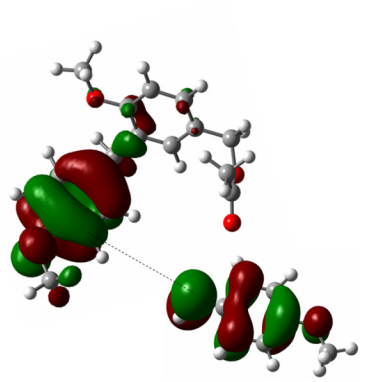

a)

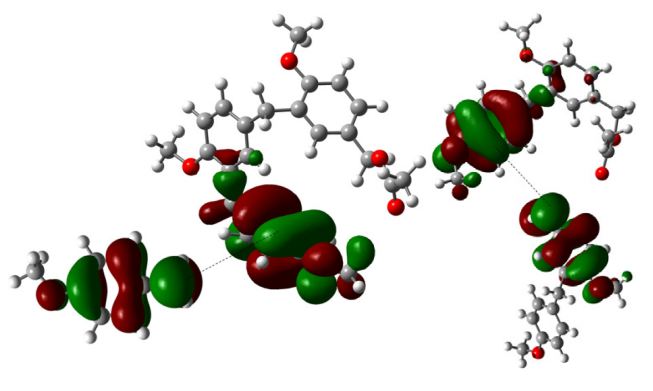

b) c)

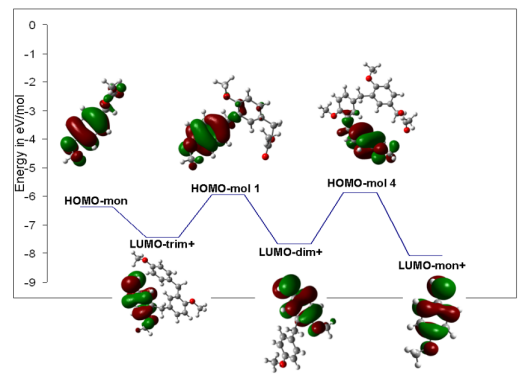

d) 
Figure 6. a) The HOMO of para-methoxybenzyl acetate and the LUMO of the methoxybenzyl carbenium ion that yield oligomer 4. b) The DM of the carbenium ion must be aligned towards the methylene group of 4 . This centered orientation prevents any further substitution under the reported experimental conditions. c) The HOMO and LUMO of 4. d) The optimized B3LYP/6-311++G(d,p) geometries for 2 . The calculated NPA charges are reported in $\mathbf{e}^{-}$.

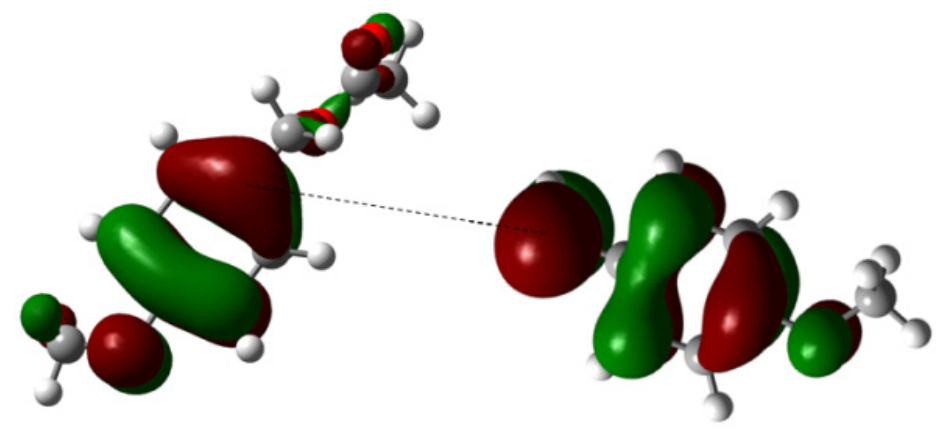

a)

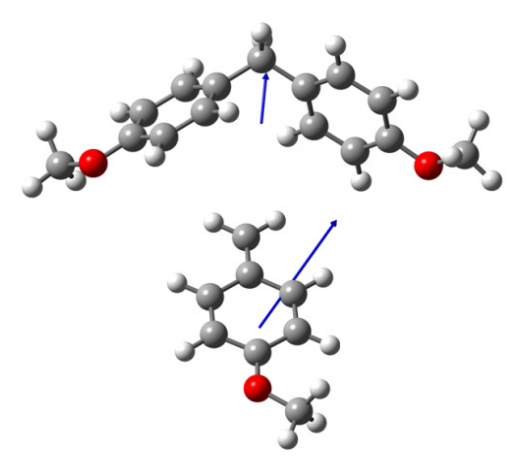

b)

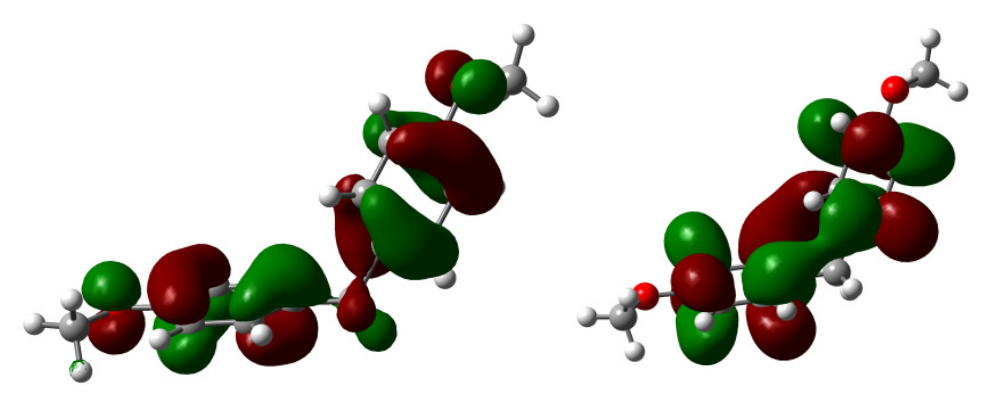

c)

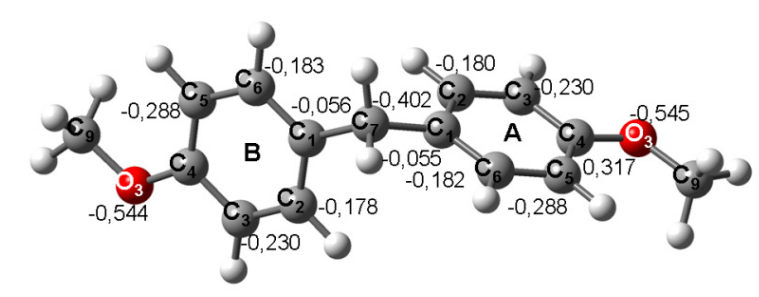

d)

The oligomer $\mathbf{5}$ may be obtained from the benzylic carbenium monomer and the dimer $\mathbf{2}$ instead of via the second pathway (Figure 5). The same condensation is suggested to explain the formation of tetramer 8; it is the primary interaction that occurs between the two DMs and the carbenium ion oriented towards the benzene ring with the major HOMO distributions. Thus, this interaction is towards any of the $\mathrm{C}$ atoms located ortho to the $\mathrm{MeO}$ group. It is also worth mentioning that these atoms have a natural atomic charge of $-0.290 \mathrm{e}^{-}$, the largest negative value in this ring. The HOMO distributions can be observed in the $\mathrm{B}$ ring. The $\mathrm{C}$ atoms located in ortho to the $\mathrm{MeO}$ group have natural atomic charges of -0.293 and -0.294 ; therefore, these sites could interact with the LUMO of the carbenium ion.

Moreover, the inhibition of the EAS was clear in 4. Its computed DM is $0.74 \mathrm{D}$ and points outwards from the methylene group. The computed HOMO distribution is widespread in an equivalent form 
over both benzene rings (Figure 6). It is also important to mention that the DM of the carbenium ion must be aligned towards the methylene group. This centered orientation and the even distribution of the HOMO and LUMO will prevent any further substitution under the reported experimental conditions. The ipso substitution plays an interesting role in the oligomerization control by blocking one side of the molecule, such as in $\mathbf{9}$ and $\mathbf{1 0}$ (Figures 7, 8 and 9). Thus, $\mathbf{9}$ and 10, which have DMs of 1.99 D and 2.25 D, respectively, and their HOMOs and LUMOs (Figure 10) located on opposite ends of the chain, favor substitution, and the chain elongation proceeds step-by-step by condensing a carbenium ion with the benzene ring that holds the HOMO orbitals. The reaction will be directed to the ortho-methoxy carbons with the largest negative charge in the ring (Figure 7).

Figure 7. a) Interaction between the LUMO of the charged carbenium dimer and the HOMO of 4 to yield the corresponding trimer 9. b) The interaction between the LUMO of methoxybenzyl carbenium ion and the HOMO of the trimer of $\mathbf{4}$ to yield the corresponding tetramer 9. c) The interaction between the LUMO of the charged carbenium trimer and the HOMO of the monomer. d) Three possible routes to obtain 9. The energy difference between the HOMO of the neutral species and the LUMO of the trimer carbenium is $\Delta \mathrm{E}_{\text {HOMO-LUMO }}=1.76 \mathrm{eV}$; therefore, this interaction is more feasible. e) Optimized B3LYP/6-311++G(d,p) geometries for 9. The calculated NPA charges are reported in $\mathbf{e}^{-}$.

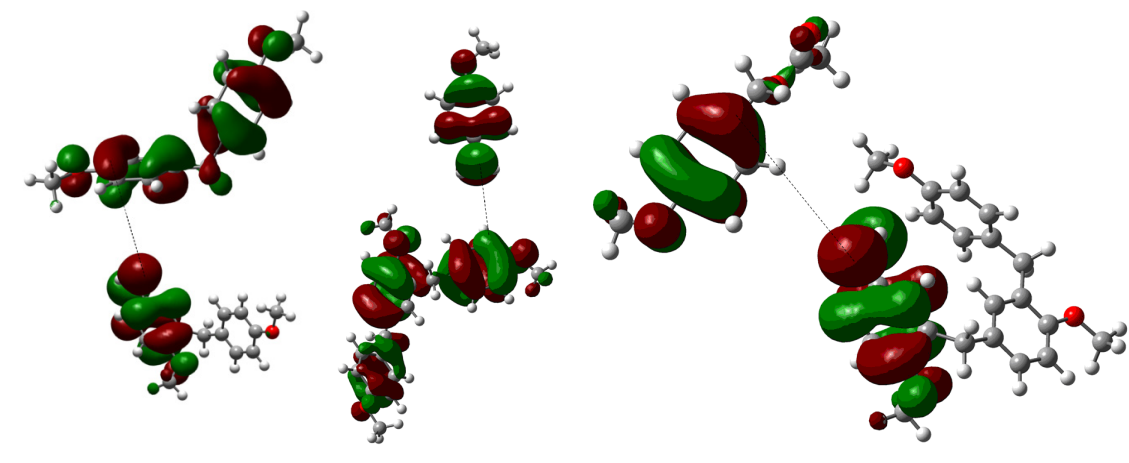

a)

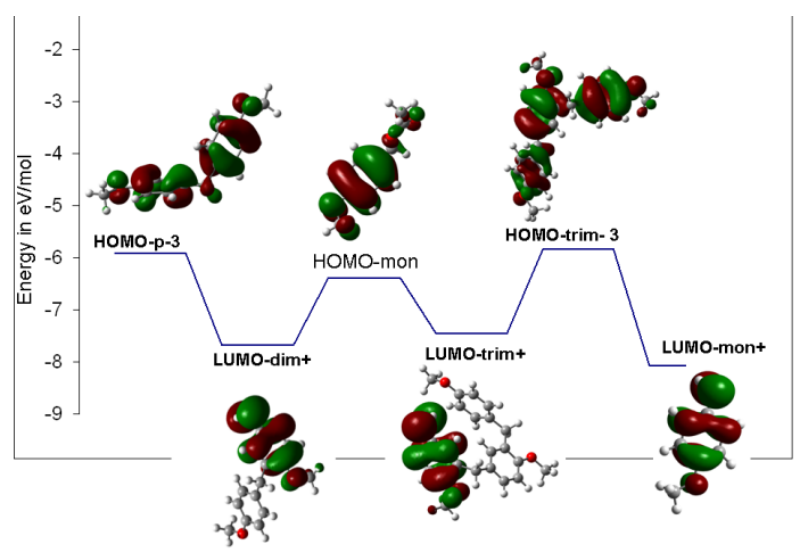

d) c)

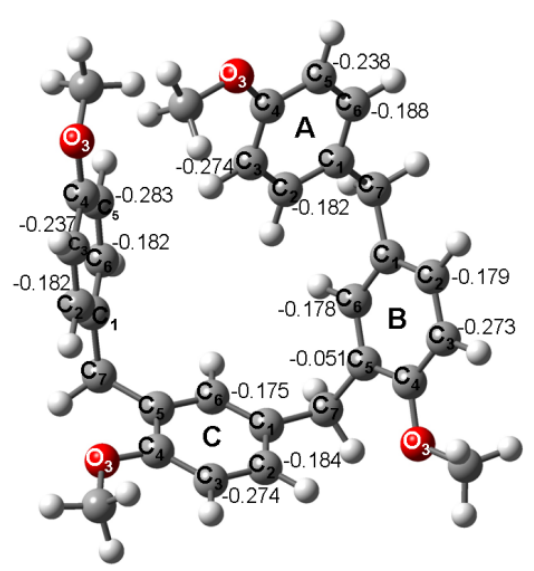

e) 
Figure 8. a) The interaction between the LUMO of the methoxybenzyl carbenium ion with the HOMO of 4 to yield the corresponding trimer, $\mathbf{4 a}$, as an intermediary of $\mathbf{9}$. b) Optimized B3LYP/6-311++G(d,p) geometries for 4a. The calculated NPA charges are reported in $\mathbf{e}^{-}$. c) Carbenium trimer of $\mathbf{4 a}$.

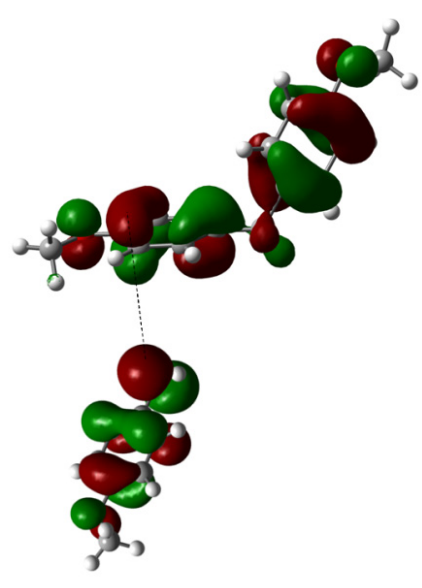

a)

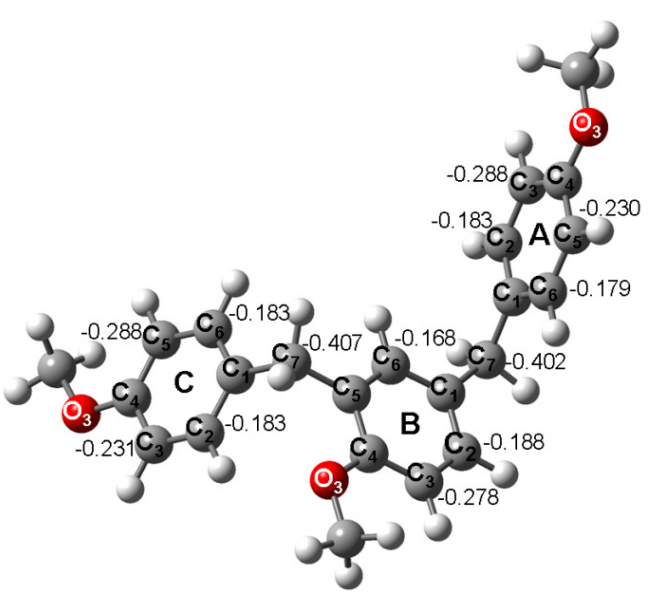

b)

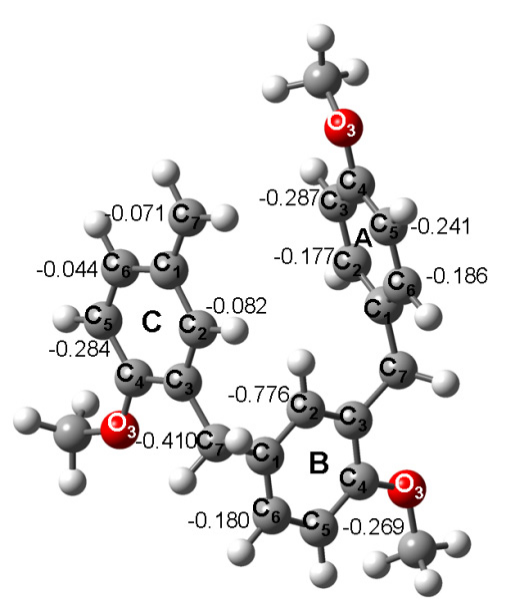

c)

Figure 9. a) The HOMO and LUMO of 9. b) The HOMO, HOMO-1 and LUMO of $\mathbf{1 0 .}$

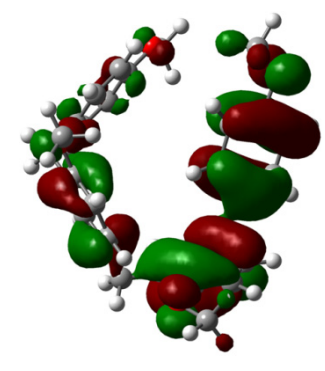

a) HOMO

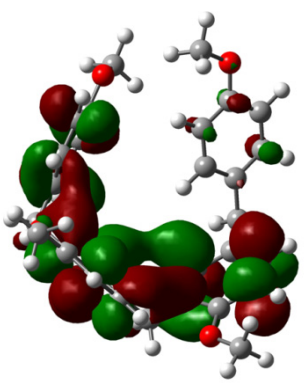

b) LUMO

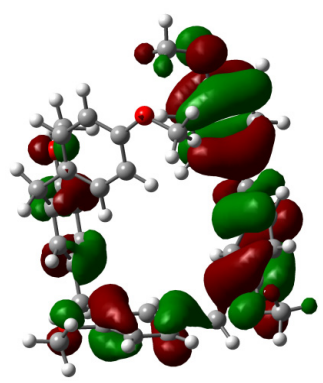

c) HOMO

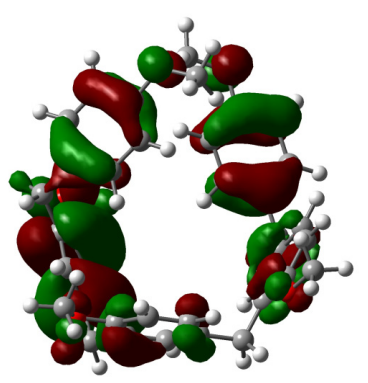

HOMO-1

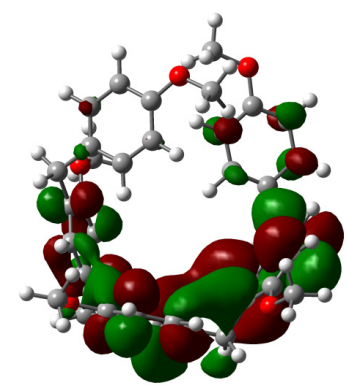

LUMO

It is convenient to note that, to classify the catalytic hydrolysis of ester molecules, organicchemistry textbooks state that the reaction precedes via AAc2 under acidic conditions and BAc2 under basic conditions [23]. The above notation indicates that the O-R bond is not commonly broken [24-29]. Under acid catalysis, an alternative but less common pathway involves the alkyl-oxygen cleavage in which an acyloxy group or its conjugated acid is the leaving group; thus, an $\mathrm{AAl}_{1}$ mechanism occurs if the alkyl substituent comes off as a stable carbenium ion. In this particular sense, it is already known that benzylic acetates are hydrolyzed by the $\mathrm{AAc}_{2}$ mechanism in dilute acid, whereas the mechanism changes to $\mathrm{AAl}_{1}$ in concentrated acid [30-34]. Additionally, little is known about acetylated benzylic alcohols as electrophiles in the EAS reaction. However, it is worth mentioning that the driving force for this process must be the catalytic acidic promotion of an $\mathrm{AAl}_{1}$ mechanism, yielding such interesting intermediates as the para-methoxybenzylic carbenium ion. Finally, it is important to note that, to the best of our knowledge, this work is the first example of a proposed $\mathrm{AAl}_{1}$ pathway when bentonitic clay is used as a heterogeneous catalyst in an EAS reaction, as supported by theoretical calculations. 
Figure 10. a) Interaction between the LUMO of the methoxybenzyl carbenium ion and the HOMO of 9 to yield the corresponding pentamer 10. b) The interaction between the LUMO of the charged carbenium dimer and the HOMO of the trimer of 4 to yield the corresponding pentamer 10. c) and d) Two possible routes to obtain 10. The energy difference between the HOMO of the trimer neutral species and the LUMO of the dimer carbenium is $\Delta \mathrm{E}_{\text {HOMO-LUMO }}=1.82 \mathrm{eV}$; therefore, this interaction is more feasible. e) The optimized B3LYP/6-311++G(d,p) geometries for 10. The calculated NPA charges are reported in $\mathbf{e}^{-}$.

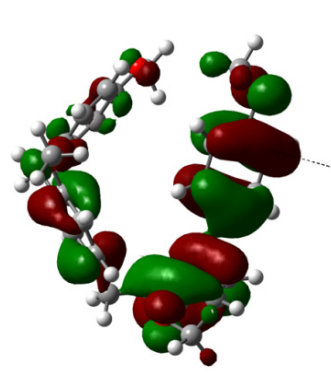

a)

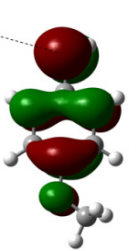

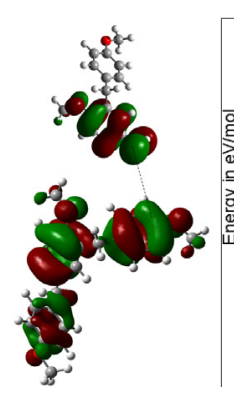

b)

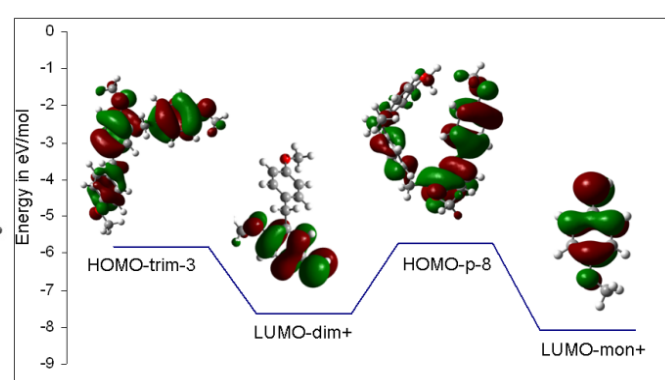

c)

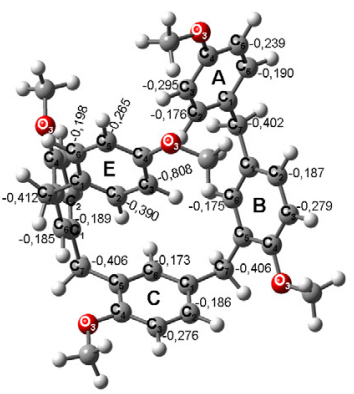

d)

Finally, from the mechanistic point of view, the catalytic action of TAFF should enhance the electrophilic character of the carbonylic substrates, facilitating the formation of para-methoxybenzyl carbonium ion. The ion is the key intermediate to understand the formation of the products. The interaction between TAFF and $\mathbf{1}$ might be due to the protonated and unprotonated active sites corresponding to the acidic Brönsted-Löwry and Lewis character of the clay (Scheme 2).

Scheme 2. Proposed reaction mechanism.

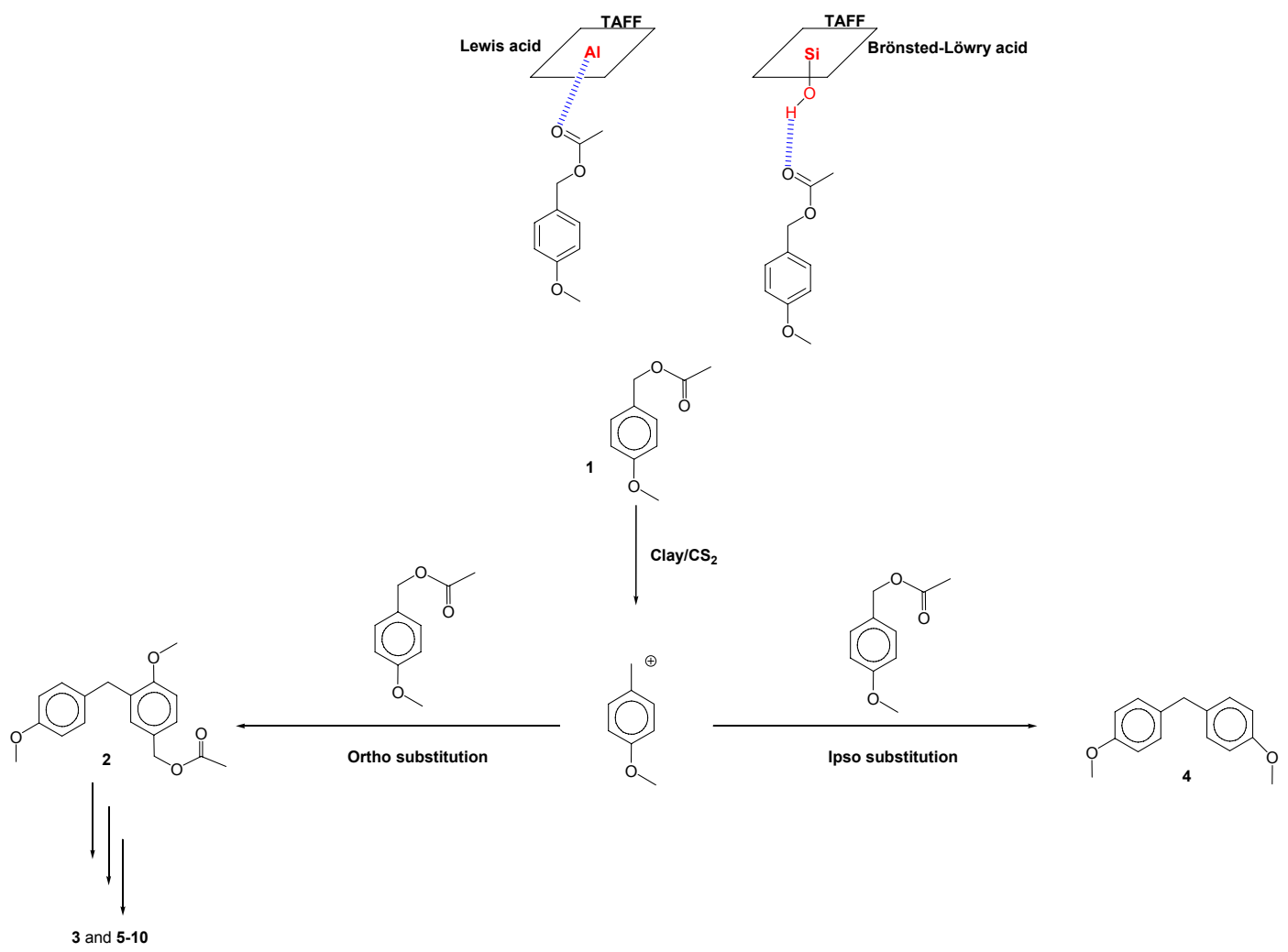




\section{Experimental}

\subsection{General}

Tonsil Actisil FF, a cheap (US $\$ 1.30 / \mathrm{kg}$ ) commercial Mexican bentonitic clay, is readily available from Tonsil Mexicana S. A. de C. V. (México City, México). Examined with X-ray fluorescence, this clay was shown to have the following composition (in \%): $\mathrm{SiO}_{2}, 74.5 ; \mathrm{Al}_{2} \mathrm{O}_{3}, 9.3 ; \mathrm{MgO}, 0.4 ; \mathrm{Fe}_{2} \mathrm{O}_{3}$, 1.3; $\mathrm{CaO}, 4.0 ; \mathrm{K}_{2} \mathrm{O}, 0.4 ; \mathrm{TiO}_{2}, 0.4 ; \mathrm{H}_{2} \mathrm{O}, 9.7$. X-ray thermodiffractograms show that the laminar structure is unstable above $150{ }^{\circ} \mathrm{C}$. Quartz and cristobalite are also important components in the clay composition, as observed by X-ray diffraction. The corresponding BET surface area is $198.718 \mathrm{~m}^{2} \mathrm{~g}^{-1}$, and the pore volume and average pore diameter are $32.04 \times 10^{-2} \mathrm{~cm}^{3} \mathrm{~g}^{-1}$ and $77.8 \AA$, respectively. It is worth mentioning that a detailed characterization of the clay $\left({ }^{29} \mathrm{Si}\right.$ and ${ }^{27} \mathrm{Al}$ MAS-NMR, SEM, IR-Py, DTA, TG, and Ho) has already been performed and reported by our research group [12]. The particle size is 325 mesh. The organic reagent 4-methoxybenzylacetate was prepared by the acetylation of 4methoxy-benzyl alcohol (Merck) with pyridine and acetyl chloride and was further purified by $\mathrm{SiO}_{2}$ column chromatography using $n-\mathrm{C}_{6} \mathrm{H}_{14} /$ EtOAc as the eluent. IR spectra were recorded on a Nicolet FTIR-5SX spectrometer. The ${ }^{1} \mathrm{H}$ - and ${ }^{13} \mathrm{C}$-NMR spectra were measured in $\mathrm{CDCl}_{3}$ solution with a Varian Unity 300 (operating at $300 \mathrm{MHz}$ and $75 \mathrm{MHz}$, respectively) using tetramethylsilane as an internal standard. Mass spectra were obtained with a JEOL JMS AX505HA mass spectrometer. For thin-layer chromatographic (TLC) analyses, Merck precoated TLC plates (silica gel $60 \mathrm{~F}_{254}, 0.25 \mathrm{~mm}$, Art 5715) were used.

\subsection{Oligomerization of p-methoxybenzyl acetate with Tonsil}

The typical procedure at room temperature is as follows: a suspension of $p$-methoxybenzyl acetate $(1,5.0 \mathrm{~g})$, carbon disulfide $(40 \mathrm{~mL})$ and the bentonitic earth $(1.0 \mathrm{~g})$ was vigorously stirred at room temperature until disappearance of the starting material, which occurred after $76 \mathrm{~h}$. The reaction was conveniently monitored by TLC. The clay was eliminated by filtration through Celite and washed with ethyl acetate $(3 \times 10 \mathrm{~mL})$. The combined filtrates were dried on anhydrous $\mathrm{Na}_{2} \mathrm{SO}_{4}$, and the solvent was eliminated under reduced pressure. The residue was subjected to chromatography on a silica-gel column using $n-\mathrm{C}_{6} \mathrm{H}_{14} /$ EtOAc as the eluent, affording phenylmethanes 2-4 and linear oligomers 5-8. The typical procedure at reflux is identical to the above procedure, but the chromatography afforded in that case the linear oligomers 9 and $\mathbf{1 0}$.

3-(4-Methoxybenzyl)-4-methoxybenzyl acetate (2). Syrupy yellow oil, isolated in 3.8\% yield, $\left(\mathrm{C}_{18} \mathrm{H}_{20} \mathrm{O}_{4}\right)$. IR (film, $\left.\mathrm{cm}^{-1}\right): 3,007,2,953,2,836,1,735(\mathrm{C}=\mathrm{O}), 1,464,1,263$, and $1,032(\mathrm{C}-\mathrm{O}) .{ }^{1} \mathrm{H}-$ NMR $\delta: 2.05\left(3 \mathrm{H}, \mathrm{s}, \mathrm{CH}_{3}\right), 3.77\left(3 \mathrm{H}, \mathrm{s}, \mathrm{CH}_{3}-\mathrm{O}\right), 3.78\left(3 \mathrm{H}, \mathrm{s}, \mathrm{CH}_{3}-\mathrm{O}\right), 3.90\left(2 \mathrm{H}, \mathrm{s}, \mathrm{Ar}_{-} \mathrm{CH}_{2}-\mathrm{Ar}\right), 4.98$ $\left(2 \mathrm{H}, \mathrm{s}, \mathrm{CH}_{2} \mathrm{O}\right), 6.80-6.85$ (3H, m, Ar), 7.05-7.21 (4H, m, Ar), ${ }^{13} \mathrm{C}-\mathrm{NMR} \delta: 21\left(\mathrm{CH}_{3}\right), 35\left(\mathrm{CH}_{2}\right), 56$ $\left(2 \mathrm{C}, \mathrm{CH}_{3} \mathrm{O}\right), 66\left(\mathrm{CH}_{2} \mathrm{O}\right), 110,114,128,134,156$ and $158(\mathrm{C}, \mathrm{Ar}) .171(\mathrm{C}=\mathrm{O}) . \mathrm{MS} m / z: 300\left[\mathrm{M}^{+}\right.$, 100\%], $241\left[\mathrm{M}-\mathrm{AcO}^{+}\right.$(54), 225 (17), 209 (16), 137 (18), 121(50), 91(10).

1-(2-Methoxy-5-methylbenzyl)-4-methoxybenzene (3). White needles m.p. $64-66 \quad{ }^{\circ} \mathrm{C}, \quad 0.42 \%$ $\left(\mathrm{C}_{16} \mathrm{H}_{18} \mathrm{O}_{2}\right)$. IR $\left(\mathrm{CDCl}_{3} \mathrm{~cm}^{-1}\right): 3,032,2,919,2,835,1,466,1,442,\left(\mathrm{CH}_{2}, \mathrm{CH}_{3}\right)$ 1,250, 1,032 (C-O). ${ }^{1} \mathrm{H}-$ 
NMR $\delta: 2.23\left(3 \mathrm{H}, \mathrm{s}, \mathrm{CH}_{3}\right), 3.77\left(3 \mathrm{H}, \mathrm{s}, \mathrm{CH}_{3} \mathrm{O}\right), 3.78\left(3 \mathrm{H}, \mathrm{s}, \mathrm{CH}_{3} \mathrm{O}\right), 3.88\left(2 \mathrm{H}, \mathrm{s}, \mathrm{CH}_{2}\right) 6.7-6.9(3 \mathrm{H}, \mathrm{m}$, $\mathrm{Ar}), 6.7-7.11,\left(4 \mathrm{H}, \mathrm{d}, \mathrm{Ar}, J=8.7,8.4 \mathrm{~Hz} \mathrm{~A} \mathrm{~B}_{2}\right) ;{ }^{13} \mathrm{C}-\mathrm{NMR} \delta: 22\left(\mathrm{CH}_{3}\right), 35\left(\mathrm{CH}_{2}\right), 56\left(\mathrm{CH}_{3} \mathrm{O}\right), 111$, 114, 127, 130, $131.5(\mathrm{C}, \mathrm{Ar}), 171(\mathrm{C}=\mathrm{O}) . \mathrm{MS} \mathrm{m} / z: 242$ [M $\left.^{+}, 100 \%\right], 227$ [M-Me] ${ }^{+}$(35), $211[\mathrm{M}-\mathrm{OMe}]^{+}$ (43), 195 (13), 174 (17), 121 (46), 91 (15)

Bis(4-methoxyphenyl)methane (4). Syrupy yellow oil $0.3 \%\left(\mathrm{C}_{15} \mathrm{H}_{16} \mathrm{O}_{2}\right)$. IR $\left(\mathrm{CHCl}_{3}\right.$, film, $\left.\mathrm{cm}^{-1}\right): 3,005$, 2,920, 2,839, 1,511, 1,457, 1,435, 1,252, 1,027. ${ }^{1} \mathrm{H}-\mathrm{NMR} \delta: 3.78\left(6 \mathrm{H}, \mathrm{s}, \mathrm{CH}_{3} \mathrm{O}\right), 3.86\left(2 \mathrm{H}, \mathrm{s}, \mathrm{CH}_{2}\right), 6.8$ $(4 \mathrm{H}, \mathrm{d}, J=9 \mathrm{~Hz}, \mathrm{Ar}), 7.05(4 \mathrm{H}, \mathrm{d}, J=8.4 \mathrm{~Hz}, \mathrm{Ar}) \mathrm{A}_{2} \mathrm{~B}_{2} \cdot{ }^{13} \mathrm{C}-\mathrm{NMR} \delta: 40\left(\mathrm{CH}_{2}\right), 56\left(2 \mathrm{C}, \mathrm{CH}_{3} \mathrm{O}\right), 114$ (4C, Ar $o-\mathrm{H}_{3} \mathrm{CO}-\mathrm{C}-\underline{\mathrm{CH}}$ ), 130 (4C, Ar, $\left.m-\mathrm{H}_{3} \mathrm{CO}-\mathrm{C}-\mathrm{CH}-\underline{\mathrm{CH}}\right) 134$ (2C Ar, ipso), 158 (2C, Ar, $\mathrm{H}_{3} \mathrm{CO}-\underline{\mathrm{C}}$ ). MS m/z: $228\left[\mathrm{M}^{+}, 100 \%\right], 227[\mathrm{M}-\mathrm{H}]^{+}$(55), 197 [M-OMe] $^{+}$(85), 121 (28), 114 (12), 91 (7), 77 (4).

3-(3-(4-Methoxybenzyl)-4-methoxybenzyl)-4-methoxybenzyl acetate (5). Syrupy yellow oil 1.3\% $\left(\mathrm{C}_{26} \mathrm{H}_{28} \mathrm{O}_{5}\right)$. IR $\left(\mathrm{CHCl}_{3}\right.$, film, $\left.\mathrm{cm}^{-1}\right): 2,835,1,736,(\mathrm{C}=\mathrm{O})$ 1,463, 1,441, 1,248, 1,033. ${ }^{1} \mathrm{H}-\mathrm{NMR} \delta: 2.05$ $\left(3 \mathrm{H}, \mathrm{s}, \mathrm{CH}_{3}\right), 3.77\left(9 \mathrm{H}, \mathrm{m}, \mathrm{CH}_{3} \mathrm{O}\right), 3.85,3.88\left(4 \mathrm{H}, \mathrm{s}, 2 \mathrm{CH}_{2}, 4.98\left(2 \mathrm{H}, \mathrm{s}, \mathrm{CH}_{2} \mathrm{O}\right), 6.75-7.20(10 \mathrm{H}, \mathrm{m}\right.$, Ar). ${ }^{13} \mathrm{C}-\mathrm{NMR} \delta: 21\left(\mathrm{CH}_{3}\right), 35\left(\mathrm{CH}_{2}\right), 56\left(\mathrm{CH}_{3} \mathrm{O}\right) 66\left(\mathrm{CH}_{2} \mathrm{O}\right) 110,114,128-134,156-158(\mathrm{Ar}), 171$ $(\mathrm{C}=\mathrm{O}): \mathrm{MS} \mathrm{m} / z: 420\left[\mathrm{M}^{+}, 37 \%\right], 360{\text { [M-AcOH}]^{+}}^{(100),} 345$ [M-AcOH-Me] $^{+}$(56), 299 (10), 239 (12), 227 (10), 165 (6), $121(90), 91(6)$.

(3-(3-(4-Methoxybenzyl)-4-methoxybenzyl)-4-methoxyphenyl)methanol (6). Syrupy yellow oil 0.0075\% $\left(\mathrm{C}_{24} \mathrm{H}_{26} \mathrm{O}_{4}\right)$. IR $\left(\mathrm{CHCl}_{3}\right.$, film, $\left.\mathrm{cm}^{-1}\right): 3,425(\mathrm{OH}), 2,850,2,928,1,502,1,247,1,033,1,463,835$. ${ }^{1} \mathrm{H}-\mathrm{NMR} \delta: 3.77\left(9 \mathrm{H}, \mathrm{s}, \mathrm{CH}_{3} \mathrm{O}\right), 3.84\left(2 \mathrm{H}, \mathrm{s}, \mathrm{CH}_{2}\right), 3.86\left(2 \mathrm{H}, \mathrm{s}, \mathrm{CH}_{2}\right), 4.54\left(2 \mathrm{H}, \mathrm{s}, \mathrm{CH}_{2}\right), 6.7-7.18$ $\left.(10 \mathrm{H}, \mathrm{m}, \mathrm{Ar}) ;{ }^{13} \mathrm{C}-\mathrm{NMR} \delta: 30\left(\mathrm{CH}_{2}\right), 35\left(\mathrm{CH}_{3} \mathrm{O}\right) 65\left(\mathrm{CH}_{2} \mathrm{O}\right) 110,114,126-132(\mathrm{Ar}) ; \mathrm{MS} \mathrm{m} / z\right) 378\left[\mathrm{M}^{+}\right.$,

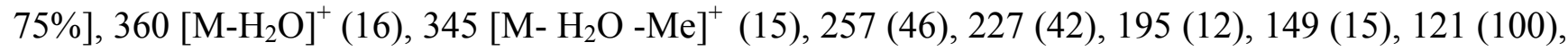
97 (11), 81 (16), 69 (34), 41 (25).

4-(2-Methoxy-5-methylbenzyl)-2-(4-methoxybenzyl)-1-methoxybenzene (7). Syrupy yellow oil 0.58\% $\left(\mathrm{C}_{24} \mathrm{H}_{26} \mathrm{O}_{4}\right)$. IR $\left(\mathrm{CHCl}_{3}\right.$, film, $\left.\mathrm{cm}^{-1}\right): 3,032,2,929,2,833,1,520,1,463,1,461,1,260,1,035 .{ }^{1} \mathrm{H}-\mathrm{NMR} \delta$ : $2.21\left(3 \mathrm{H}, \mathrm{s}, \mathrm{CH}_{3}\right), 3.73\left(3 \mathrm{H}, \mathrm{s}, \mathrm{CH}_{3} \mathrm{O}\right), 3.77\left(3 \mathrm{H}, \mathrm{s}, \mathrm{CH}_{3} \mathrm{O}\right), 3.81\left(2 \mathrm{H}, \mathrm{s}, \mathrm{CH}_{2}\right), 3.86\left(2 \mathrm{H}, \mathrm{s}, \mathrm{CH}_{2}\right)$, 6.71-7.12 (10H, m, Ar); ${ }^{13} \mathrm{C}-\mathrm{NMR} \delta: 21\left(\mathrm{CH}_{3}\right), 35\left(\mathrm{CH}_{2}\right) 56\left(\mathrm{CH}_{3} \mathrm{O}\right), 110,114,127,130,131,(\mathrm{Ar})$; MS m/z $362\left[\right.$ [M $\left.^{+}, 100 \%\right], 347$ [M-Me] ${ }^{+}(8), 331$ [M-OMe] $^{+}(10), 241$ (77), 227 (41), 195 (6), 181 (7), $121(95), 105$ (10), 91 (6).

3-(3-(3-(4-Methoxybenzyl)-4-methoxybenzyl)-4-methoxybenzyl)-4-methoxybenzyl acetate (8). Syrupy yellow oil $0.037 \%\left(\mathrm{C}_{34} \mathrm{H}_{36} \mathrm{O}_{6}\right)$; IR $\left(\mathrm{CHCl}_{3}\right.$, film, $\left.\mathrm{cm}^{-1}\right): 2,925,2,835,1,736,(\mathrm{C}=\mathrm{O}), 1,619,1,254$, $1,033 \mathrm{~cm}^{-1} .{ }^{1} \mathrm{H}-\mathrm{NMR} \delta: 2.04\left(3 \mathrm{H}, \mathrm{s}, \mathrm{CH}_{3}\right), 3.73-3.77\left(12 \mathrm{H}, \mathrm{s}, \mathrm{CH}_{3} \mathrm{O}\right), 3.80-3.85\left(6 \mathrm{H}, \mathrm{s}, \mathrm{CH}_{2}\right), 4.95$ $\left(2 \mathrm{H}, \mathrm{s}, \mathrm{CH}_{2}\right), 6.7-7.25(12 \mathrm{H}, \mathrm{m}, \mathrm{Ar}) ;{ }^{13} \mathrm{C}-\mathrm{NMR} \delta: 21\left(\mathrm{CH}_{3}\right), 35,30,\left(\mathrm{CH}_{2}\right) 56\left(\mathrm{CH}_{3} \mathrm{O}\right), 67\left(\mathrm{CH}_{2} \mathrm{O}\right), 171$ $(\mathrm{C}=\mathrm{O}), 110,114,127-130,(\mathrm{Ar}) ; \mathrm{MS} m / z 480\left[\mathrm{M}^{+}, 100 \%\right], 465$ [M-Me] $^{+}(23), 449$ [M-OMe $^{+}(11), 345$ (6), 240 (22), $121(83), 91(4), 57$ (6).

1-(5-(5-(4-Methoxybenzyl)-2-methoxybenzyl)-2-methoxybenzyl)-4-methoxybenzene (9). Syrupy yellow oil $0.39 \%\left(\mathrm{C}_{34} \mathrm{H}_{36} \mathrm{O}_{6}\right)$; IR $\left(\mathrm{CHCl}_{3}\right.$, film, $\left.\mathrm{cm}^{-1}\right): 2,928,2,837,1,611,1,246,1,043 .{ }^{1} \mathrm{H}-\mathrm{NMR} \delta: 3.73(3 \mathrm{H}$, $\left.\mathrm{s}, \mathrm{CH}_{2} \mathrm{O}\right), 3.77\left(6 \mathrm{H}, \mathrm{s}, \mathrm{CH}_{3} \mathrm{O}\right), 3.79\left(4 \mathrm{H}, \mathrm{s}, \mathrm{CH}_{2}\right), 3.86\left(2 \mathrm{H}, \mathrm{s}, \mathrm{CH}_{2}\right), 6.7-7.12(14 \mathrm{H}, \mathrm{m}, \mathrm{Ar}) ;{ }^{13} \mathrm{C}-\mathrm{NMR}$ $\delta: 35,41\left(\mathrm{CH}_{2}\right), 55\left(\mathrm{CH}_{2} \mathrm{O}\right), 110,114,126-134,(\mathrm{Ar}) ; \mathrm{MS} \mathrm{m} / z 480\left[\mathrm{M}^{+}, 100 \%\right], 437$ [M-OMe] ${ }^{+}$(7), 347(32), 241(10), 227(31), 121(50). 
2-(3-(4-Methoxybenzyl)-4-methoxybenzyl)-4-(5-(4-methoxybenzyl)-2-methoxybenzyl)-1-ethoxybenzene (10). Syrupy yellow oil $0.94 \%\left(\mathrm{C}_{42} \mathrm{H}_{44} \mathrm{O}_{7}\right)$; IR $\left(\mathrm{CHCl}_{3}\right.$, film, $\left.\mathrm{cm}^{-1}\right)$ : 2,936, 2,834, 1,736, $(\mathrm{C}=\mathrm{O}), 1,258$, 1,033. ${ }^{1} \mathrm{H}-\mathrm{NMR} \delta: 2.10\left(3 \mathrm{H}, \mathrm{s}, \mathrm{CH}_{3}\right), 371\left(9 \mathrm{H}, \mathrm{s}, \mathrm{CH}_{3} \mathrm{O}\right), 3.75\left(6 \mathrm{H}, \mathrm{s}, \mathrm{CH}_{3} \mathrm{O}\right), 3.79\left(4 \mathrm{H}, \mathrm{s}, \mathrm{CH}_{2}\right), 3.82$ $\left.\left(2 \mathrm{H}, \mathrm{s}, \mathrm{CH}_{2}\right), 3.84\left(2 \mathrm{H}, \mathrm{s}, \mathrm{CH}_{2}\right), 4.902 \mathrm{H}, \mathrm{s}, \mathrm{CH}_{2} \mathrm{O}\right), 6.7-7.25(16 \mathrm{H}, \mathrm{Ar}) ;{ }^{13} \mathrm{C}-\mathrm{NMR} \delta: 22\left(\mathrm{CH}_{3}\right), 35$ $\left(\mathrm{CH}_{2}\right), 55\left(\mathrm{CH}_{3} \mathrm{O}\right), 66\left(\mathrm{CH}_{2} \mathrm{O}\right), 110,113,127-134,155,158,(16 \mathrm{H}, \mathrm{Ar}) ; \mathrm{MS} m / z 660\left[\mathrm{M}^{+}, 5 \%\right], 600$ [M-AcOH] (100), 479 (55), 467 (11), 368 (22), 300 (11), 241 (23), 135 (22), 121 (70), 69 (26), 57 (39).

\subsection{Theoretical calculations}

The geometries and electronic structures of all compounds were determined by calculations carried out in the spin-restricted and spin-unrestricted formalisms for closed-shell and open-shell systems, respectively. In addition, the corresponding geometry optimizations were performed by electronicstructure approaches using density-functional theory (DFT) and specifically the functional B3LYP $[35,36]$. This functional is Becke's three-parameter functional in which the correlation functional is provided by the Lee, Yang, and Parr expression (LYP) functional. B3LYP proved to be a suitable method because it includes the electron-correlation effects to some extent. In other words, this scheme was used in conjunction with the split-valence polarized basis set and diffuses, 6-311++G(d,p) [37-40], as implemented in Gaussian 03 [41].

The located transition state (TS) was confirmed through the analysis of vibration frequencies, which are single imaginary frequencies, defined along the reaction coordinate presented by such states. The optimized structures were confirmed as local minima by estimating their normal vibrations and by the absence of imaginary frequencies. The natural atomic charges, dipole moment and HOMO (highest occupied molecular orbital) and LUMO (lowest unoccupied molecular orbital) were used to analyze the electrophilic or nucleophilic character involved in the reactivity of the para-methoxybenzyl acetate molecule. In addition, these properties were determined for the equilibrium geometries. The structures and the properties were visualized with the GaussView package coupled to Gaussian 03. The naturalpopulation analysis (NPA) was developed to calculate the atomic charges of molecular wave functions in general atomic-orbital basis sets. NPA is an alternative to conventional Mulliken population analysis and exhibits improved numerical stability [42,43]. This method was used to determine the charge of the studied molecules. The NBO 3.1 program was used as implemented in Gaussian 09 at the B3LYP theoretical level. The NBO analysis transforms the canonical delocalized Hartree-Fock (HF) MOs into localized orbitals that are closely tied to chemical-bonding concepts. This process involves the sequential transformation of non-orthogonal atomic orbitals (AOs) into sets of NAOs, NHOs, and NBOs. Each of these localized basis sets is complete and describes the wave functions in the most economical method because electron density and other properties are described by the minimal amount of filled orbitals in the most rapidly convergent way.

\section{Conclusions}

The oligomerization of para-methoxybenzyl acetate with Tonsil Actisil FF (TAFF), a commercial bentonite clay, provided isomeric diphenylmethane and linear oligomers with a progressive number of units. This work is the first example in which an $\mathrm{AAl}_{1}$ pathway is proposed when bentonitic clay is 
used as a heterogeneous catalyst in an EAS reaction. The corresponding conclusion was based on the computed dipole moments, the HOMO/LUMO distributions and a natural-populations analysis of the studied molecules.

\section{Acknowledgements}

Financial support from DGAPA-UNAM under Projects PAPIIT: IN-500597, PAPIME: PE201905 and CONACyT-México. We also want to thank DGSCA-UNAM for the generous time in their KanBalam Supercomputer.

\section{References and Notes}

1. Berger, N.; Jay, P. A new impregnant for HV power capacitors. IEEE Trans. Elect. Insul. 1986, EJ-21, 59-63.

2. Kunio, S.; Takao, T.; Toshikatsu, S. Alkyldiphenylmethane solvents for pesticides. Jpn. Kokai. Tokkyo Koho JP 09025202, 28 January 1997.

3. Pisanenko, D.A.; Avilov, B.O.; Likhnitskii, K.V. Corrosion-Protecting Properties of Products of Pyridine Quaternization with Chloromethylated Benzyltoluenes. Russ. J. Appl. Chem. 2010, 83, 1663-1665.

4. Miranda, R.; Rios, H.; Delgado, F.; Castro, M.; Cogordan, A.; Salmon, M. Characterization of a bentonitic clay and its application as catalyst in the preparation of benzyltoluenes and oligotoluenes. Appl. Catal. A 2003, 244, 217-233.

5. Salmon, M.; Angeles, E.; Miranda, R. Bromine/bentonite earth system, promoter of phenylmethanes from toluene. Chem. Commun. 1990, 17, 1188-1190.

6. Salmon, M.; Zavala, N.; Martinez, M.; Miranda, R.; Cruz, R.; Cardenas, J.; Gavino, R.; Cabrera, A. Cyclic and linear oligomerization reaction of 3,4,5-trimethoxybenzyl alcohol with a bentoniteclay. Tetrahedron Lett. 1994, 35, 5797-5800.

7. Cabrera, A.; Peon, J.; Velasco, L.; Miranda, R.; Salmon, A.; Salmon, M. Clay-mediated cyclooligomerization of olefin oxides: A one-pot route to crown ethers. J. Mol. Catal. A Chem. 1995, 104, L5-L7.

8. Salmon, M.; Zavala, N.; Cabrera, A.; Cardenas, J.; Gavino, R.; Miranda, R.; Martinez, M. Aromatic substitution reactions of benzyl derivatives with a bentonite clay. J. Mol. Catal. A: Chem. 1995, 104, L127-L129.

9. Salmon, M.; Perez-Luna, M.; Lopez-Franco, C.; Hernandez, E.; Alvarez-Ramirez, R.A.; LopezOrtega, A.; Dominguez, J.M. Catalytic conversion of proplyene oxide on a super acid sulfonic clay (SASC) system. J. Mol. Catal. A Chem. 1997, 122, 169-174.

10. Miranda, R.; Osnaya, R.; Garduno, R.; Delgado, F.; Alvarez, C.; Salmon, M. A general alternative to obtain S.S-Acetals using Taff, a bentonitic clay. Synth. Commun. 2001, 31, 1587-1597.

11. Cruz-Almanza, R.; Shiba-Matzumoto, I.; Fuentes, A.; Martinez, M.; Cabrera, A.; Cardenas, J.; Salmon, M. Oligomerization of benzylic alcohols and its mechanism. J. Mol. Catal. A Chem. 1997, 126, 161-168. 
12. Miranda, R.; Rios, H.; Delgado, F.; Castro, M.; Cogordan, A.; Salmon, M. Characterization of a bentonitic clay and its application as catalyst in the preparation of benzyltoluenes and oligotoluenes. Appl. Catal. A 2003, 244, 217-233.

13. Miranda, R.; Arroyo, G.A.; Penieres, G.; Delgado, F.; Cabrera, A.; Alvarez, C.; Salmon, M. Preparative heterocyclic chemistry using tonsil a bentonitic clay; 1981 to 2003. Trends Heterocycl. Chem. 2003, 9, 195-235.

14. Morales-Serna, J.A.; López-Duran, L.E.; Castro, M.; Sansores, L.E.; Zolotukhin, M.; Salmón, M. Oligomerization of 3,5-Dimethyl Benzyl Alcohol Promoted by Clay: Experimental and Theoretical Study. Molecules 2010, 15, 8156-8168.

15. Beltrame, P.; Zuretti, G. Kinetic studies for processes of liquid-phase alkylation of aromatics over solid acid catalysts. Green Chem. 2004, 6, 7-13.

16. Ardizzone, S.A.; Beltrame, P.; Zuretti, G. Kinetics of the reaction of toluene with benzyl alcohol over sulfated zirconia. Appl. Catal. A 2006, 314, 240-247.

17. Beltrame, P.; Zuretti, G. Kinetics of the reaction of toluene with benzyl alcohol over a Nafionsilica composite. Appl. Catal. A 2005, 283, 33-38.

18. Salcedo, R.; Salmón, M.; Cabrera, A.; Sansores, L.E. Clay promoted oligomerisation of benzylic alcohols via EAS pathway: A theroretical study. J. Mol. Struct. Theochem 2000, 497, 75-82.

19. Vargas-Rodriguez, Y.M.; Beltran, H.I.; Vazquez-Labastida, E.; Linares-Lopez, C.; Salmon, M. Synthesis and characterization of montmorillonite clays with modulable porosity induced with acids and superacids. J. Mater. Res. 2007, 22, 788-800.

20. Susuky, H.; Nakamura, K. The reaction of polysubstituted aromatics. X. An easy conversion of 2,3,4,5,6-pentamethylbenzyl derivatives to hexamethylbenzene by catalysis of sulfuric acid. Bull. Chem. Soc. Jpn. 1968, 41, 2197-2199.

21. Nyberg, K. Friedel-Crafts benzylation by benzyl acetates using trifluoromethanesulfonic acid as a catalyst. Chem. Scr. 1973, 4, 143-144.

22. Johnstone, R.A.W.; Wilby, A.H.; Entwistle, L.D. Heterogeneous catalytic transfer hydrogenation and its relation to other methods for reduction of organic compounds. Chem. Rev. 1985, 85, 129-170.

23. Smith, M.B.; March, J. Advanced Organic Chemistry, 5th ed.; Wiley: Toronto, Canada, 2001; pp. $469-477$.

24. Piiskop, S.; Hagu, H.; Järv, J.; Salmar, S.; Tuulmets, A. Sonication effects on ester hydrolysis in alcohol-water mixtures. Proc. Estonian Acad. Sci. Chem. 2007, 56, 199-206.

25. Hori, K.; Ilenaga, Y.; Arata, K.; Takahashi, T.; Kasai, K.; Noguchi, Y.; Sumimoto, M.; Yamamoto, H. Theoretical study on the reaction mechanism for the hydrolysis of esters and amides under acidic conditions. Tetrahedron 2007, 63, 1264-1269.

26. Librovich, N.B.; Tarakanova, E.G. Quantum-chemical calculation of the structure of an inert complex in the acid-catalyzed hydrolysis of esters. Doklady Phys. Chem. 2006, 410, 275-277.

27. Rispens, T.; Lensink, M.F.; Berendsen, H.J.C.; Engberts, J.B.F.N. Molecular dynamics simulation of the effect of hydrophobic cosolutes on the neutral hydrolysis of an activated ester. J. Phys. Chem. B 2004, 108, 5483-5488.

28. Chaudry, U.A.; Popelier, P.L.A. Ester hydrolysis rate constant prediction from quantum topological molecular similarity descriptors. J. Phys. Chem. A 2003, 107, 4578-4582. 
29. Zhan, C.-G.; Landry, D.W.; Ornstein, R.L. Reaction pathways and energy barriers for alkaline hydrolysis of carboxylic acid esters in water studied by a hybrid supermolecule-polarizable continuum approach. J. Am. Chem. Soc. 2000, 122, 2621-2627.

30. Yates, K. Kinetics of ester hydrolysis in concentrated acid. Acc. Chem. Res. 1971, 4, 136-144.

31. Marlier, J.F.; Frey, T.G.; Mallory, J.A.; Cleland, W.W. Multiple isotope effect study of the acidcatalyzed hydrolysis of methyl formate. J. Org. Chem. 2005, 70, 1737-1744.

32. Cox, R.A. A comparison of the mechanisms of hydrolysis of benzimidates, esters, and amides in sulfuric acid media. Can. J. Chem. 2005, 83, 1391-1399.

33. Ali, S.H.; Merch, S.Q. Kinetic study of Dowex $50 \mathrm{Wx} 8$-catalyzed esterification and hydrolysis of benzyl acetate. Ind. Eng. Chem. Res. 2009, 48, 2519-2532.

34. Limpanuparb, T.; Punyain, K.; Tantirungrotechai, Y. A DFT investigation of methanolysis and hydrolysis of triacetin. J. Mol. Struct. Theochem 2010, 955, 23-32.

35. Becke, A.D. Density-functional exchange-energy approximation with correct asymptotic behavior. Phys. Rev. A 1988, 38, 3098-3100.

36. Lee, C.; Yang, W.; Parr, R.G. Development of the colle-salvetti correlation-energy formula into a functional of the electron density. Phys. Rev. B 1988, 37, 785-789.

37. Krishnan, R.; Binkley, J.S.; Seeger, R.; Pople, J.A. Self-consistent molecular orbital methods. XX. A basis set for correlated wave functions. J. Chem. Phys. 1980, 72, 650-654.

38. Gill, P.M.W.; Johnson, B.G.; Pople, J.A.; Frisch, M.J. The performance of the Becke-Lee-YangParr (B-LYP) density functional theory with various basis sets. Chem. Phys. Lett. 1992, 197, 499-505.

39. Hariharan, P.C.; Pople, J.A. The influence of polarization functions on molecular orbital hydrogenation energies. Theor. Chim. Acta 1973, 28, 213-222.

40. Clark, T.; Chandrasekhar, J.; Spitznagel, G.W.; Schleyer, P.V.R. Efficient diffuse functionaugmented basis sets for anion calculations. III. The 3-21+G basis set for first-row elements, Li-F. J. Comp. Chem. 2004, 4, 294-301.

41. Frisch, M.J.; Trucks, G.W.; Schlegel, H.B.; Scuseria, G.; Robb, E.M.A.; Cheeseman, J.R.; Scalmani, G.; Barone, V.; Mennucci, B.; Petersson, G.A.; et al. Gaussian 03, Revision D.01; Gaussian Inc.: Wallingford, CT, USA, 2004.

42. Reed, A.E.; Weinstock, R.B.; Weinhold, F. Natural-population analysis. J. Chem. Phys. 1985, 83, 735-746.

43. Reed, A.E.; Weinhold, F. Natural bond orbital analysis of near-Hartree-Fock water dimer. $J$. Chem. Phys. 1983, 78, 4066-4073.

Sample Availability: Samples of the compounds 2-10 are available from the authors.

(C) 2011 by the authors; licensee MDPI, Basel, Switzerland. This article is an open access article distributed under the terms and conditions of the Creative Commons Attribution license (http://creativecommons.org/licenses/by/3.0/). 